\title{
Analisis Struktur Kristal Polyetilen Glicol (PEG-4000) Coated Nanopartikel Magnetite $\left(\mathrm{Fe}_{3} \mathrm{O}_{4}\right)$
}

\author{
Alfrie Musa Rampengan*,Jeferson Polii \\ a Ilmu Fisika FMIPA, Universitas Negeri Manado, Tondano, 95619, Indonesia \\ INFO ARTIKEL

\begin{tabular}{l}
\hline Diterima 03 Oktober 2019 \\
Disetujui 27 Oktober 2019 \\
\hline Key word: \\
nanoparticle $\mathrm{Fe}_{3} \mathrm{O}_{4}$ \\
crystal structures \\
\hline Kata kunci: \\
nanopartikel $\mathrm{Fe}_{3} \mathrm{O}_{4}$ \\
struktur kristal \\
\hline
\end{tabular}

\begin{abstract}
A BSTRACT
The synthesis of materials made from $\mathrm{FeSO}_{4} .7 \mathrm{H}_{2} \mathrm{O}, \mathrm{FeCl}_{3} .6 \mathrm{H}_{2} \mathrm{O}$, and $\mathrm{NH}_{4} \mathrm{OH}$ hydrocarbon materials have been synthesized using the coprecipitation method which has produced the $\mathrm{Fe}_{3} \mathrm{O}_{4}$ nanoparticle material. Crystal structure analysis of $\mathrm{Fe}_{3} \mathrm{O}_{4}$ nanoparticles can be seen from the results of material characterization using X-Ray Diffractometer which shows the diffraction peaks, namely (220) (311) (400) (511) (440) with the main peak on the index (311). Samples of $\mathrm{Fe}_{3} \mathrm{O}_{4}$ nanoparticles were modified with PEG-4000 polymer, emerging new diffraction peaks such as peaks with index (111), $\alpha-\mathrm{Fe}_{3} \mathrm{O}_{4}$ peaks, $\gamma-\mathrm{FeO}(\mathrm{OH})$ peaks and $\alpha-\mathrm{FeO}(\mathrm{OH})$ peaks. The emergence of these new peaks is due to the influence of the PEG-4000 polymer which directly shows the bond with the -OH (hydroxyl) group.
\end{abstract}

*email:

alfrierampengan@unima.ac.id

*Telp: 08114382696

\section{Pendahuluan}

Nanopartikel magnetik memiliki sifat yang sangat aplikatif dalam berbagai bidang ilmu, seperti fluida, gel magnetik, bioteknologi, biomedis, katalis, dan magnetic resonance imaging (MRI). Keberhasilan penerapan nanopartikel magnetik di berbagai bidang ilmu sangat tergantung pada stabilitas partikel pada berbagai kondisi yang berbeda. Partikel akan menjadi sangat populer ketika ukuran partikel berada pada range nano yang bergantung pada komposisi materi. Masing-masing dari nanopartikel akan menjadi domain magnetik tunggal dan menunjukkan perilaku superparamagnetik [1]. Ukuran partikel itulah yang menentukan sifat kemagnetan. Salah satu partikel magnetik yang berukuran nanometer adalah oksida besi seperti magnetit $\mathrm{Fe}_{3} \mathrm{O}_{4}$, semakin kecil ukuran butir maka nanopartikel $\mathrm{Fe}_{3} \mathrm{O}_{4}$ akan memiliki responsibilitas magnetik yang tinggi (mudah termagnetisasi oleh medan magnet eksternal). Dengan kata lain, efek superparamagnetik akan semakin dominan seiring dengan semakin kecilnya diameter butir nanopartikel $\mathrm{Fe}_{3} \mathrm{O}_{4}$ [2]. Ukuran partikel, sifat permukaan dan sifat kemagnetan adalah keunggulan dari nanopartikel magnetite sehingga sangat mudah termodifikasi dengan material lain. Salah satu sifat uniknya adalah keaktifan atom besi Fe pada permukaan nanopartikel magnetit $\mathrm{Fe}_{3} \mathrm{O}_{4}$ terhadap elemen material lain, dimana atom Fe pada permukaan nanopartikel magnetik dalam medium air berinteraksi dengan gugus hidroksil $(-\mathrm{OH})$ yang 
akan membentuk ikatan Fe-OH [3]. Sifat reaktif atom $\mathrm{Fe}$ pada permukaan nanopartikel $\mathrm{Fe}_{3} \mathrm{O}_{4}$ membuka peluang untuk dilakukannya proses modifikasi oleh polyetilen glycol (PEG). PEG adalah salah satu jenis polimer yang dapat dipakai untuk membentuk dan mengontrol ukuran partikel. PEG dapat juga berfungsi sebagai templete, yang membungkus partikel sehingga tidak terbentuk agregat lebih lanjut, disebabkan PEG menempel pada permukaan partikel dan menutupi ion positif yang bersangkutan untuk bergantung dan membesar, sehingga pada akhirnya akan diperoleh partikel dengan bentuk bulatan yang seragam. Berdasarkan keunggulan dari nanopartikel tersebut, maka perlu dilakukan analisa struktur kristal nanopartikel $\mathrm{Fe}_{3} \mathrm{O}_{4}$ dan nanopartkel $\mathrm{Fe}_{3} \mathrm{O}_{4}$ yang telah termodifikasi dengan polyetilen glycol (PEG-4000).

\section{Bahan dan Metode}

Sintesis nanopartikel $\mathrm{Fe}_{3} \mathrm{O}_{4}$ menggunakan metode kopresipitasi berbahan dasar senyawa hidrat $\mathrm{FeSO}_{4} .7 \mathrm{H}_{2} \mathrm{O} 0.005$ mol, $\mathrm{FeCl}_{3} .6 \mathrm{H}_{2} \mathrm{O} 0.001$ mol dan $\mathrm{NH}_{4} \mathrm{OH} 10 \%$. Timbanglah sebanyak 8,109 g FeCl $3.6 \mathrm{H}_{2} \mathrm{O}$ dan 4,1703 g $\mathrm{FeSO}_{4} .7 \mathrm{H}_{2} \mathrm{O}$ dengan menggunakan timbangan digital, kemudian larutkan dengan $30 \mathrm{ml}$ aquades yang diaduk hingga homogen menggunakan magnetic stirrer \pm 10 menit. Tambahkan larutan $\mathrm{NH}_{4} \mathrm{OH}$ $10 \%$ (60 ml) yang dibuat dengan mengencerkan $24 \mathrm{ml} \mathrm{NH} \mathrm{OHH}_{4}$ dengan aquades hingga $60 \mathrm{ml}$, sedikit demi sedikit dituangkan, sementara pengadukan menggunakan magnetic stirrer dengan konsentrasi suhu pengadukkan $60^{\circ} \mathrm{C}$, kecepatan pengadukkan $450 \mathrm{rpm}$, lama pengadukkan 90 menit. Endapan selanjunya dicuci menggunakan aquades hingga beberapa kali pengulangan agar garam-garam hasil reaksi lainnya yang ikut terlarut semakin terminimalisir jumlahnya di dalam sampel sehingga dapat diperoleh sampel $\mathrm{Fe}_{3} \mathrm{O}_{4}$ yang lebih murni. Sampel $\mathrm{Fe}_{3} \mathrm{O}_{4}$ yang telah dicuci selanjutnya dikeringkan menggunakan furnace dengan mengatur suhu pengeringan $80^{\circ} \mathrm{C}$ selama 120 menit. Sampel yang kering kemudian dianalisis struktur Kristal menggunakan XRD.

Nanopartikel yang telah kering dimodifikasi permukaannya menggunakan polimer PEG-4000 dengan perbandingan konsentrasi 0,5 g nanopartikel $\mathrm{Fe}_{3} \mathrm{O}_{4}$ dicampurkan ke dalam 0,5 g polimer PEG-4000 yang telah dilarutkan dalam aguades. Campuran nanopartikel dan polimer PEG-4000 selanjutnya digetarkan kembali dalam medium ultrasonik sekitar 30 menit agar semua permukaan nanopartikel dapat terlapisi dengan baik. Kemudian dibiarkan sampai kering, digerus menghasilkan serbuk. Sampel modifikasi ini yang dalam keadaan kering dianalisis struktur kristalnya menggunakan XRD.

\section{Hasil dan Pembahasan}

Fabrikasi material nanopartikel magnetite $\left(\mathrm{Fe}_{3} \mathrm{O}_{4}\right)$ menggunakan metode kopresipitasi yang terdiri dari 2 bagian yaitu pelarutan dan pengendapan, dimana parameter $\mathrm{NH}_{4} \mathrm{OH}$ konsentrasi $10 \%$, suhu sintering $60{ }^{\circ} \mathrm{C}$, dan kecepatan pengadukan $450 \mathrm{rpm}$ selama 90 menit, kemudian diendapkan dengan bantuan magnet permanen. Nanopartikel magnetite $\left(\mathrm{Fe}_{3} \mathrm{O}_{4}\right)$ tersebut dimodifikasi dengan penambahan polymer poliethylen glicol 4000 (PEG4000), dimana kedua material tersebut di analisa struktur kristalnya.

\section{Struktur Kristal $\mathrm{Fe}_{3} \mathrm{O}_{4}$ dengan X-Ray Difractometer} (XRD)

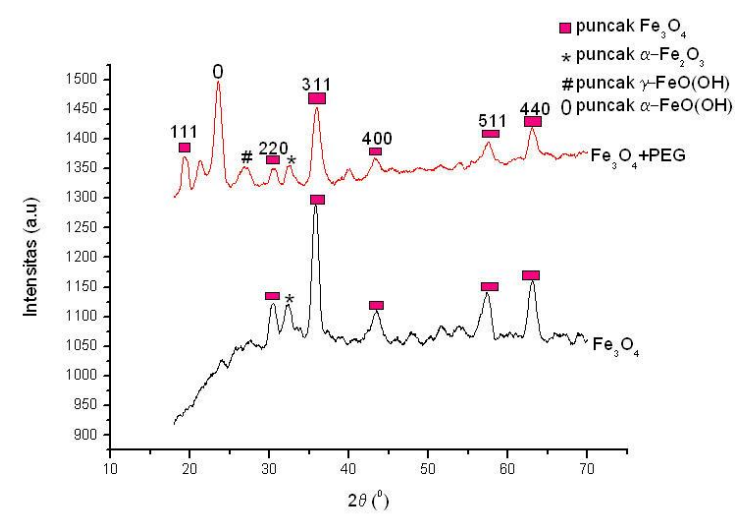

Gambar 1. Pola XRD (a) sampel nanopartikel $\mathrm{Fe}_{3} \mathrm{O}_{4}$ fasa kering, (b) sampel nanopartikel $\mathrm{Fe}_{3} \mathrm{O}_{4}$ termodifikasi oleh polimer PEG-4000

Hasil karakterisasi diperoleh dengan difraktogram hasil sintesis sampel nanopartikel $\mathrm{Fe}_{3} \mathrm{O}_{4}$ dan sampel nanopartikel $\mathrm{Fe}_{3} \mathrm{O}_{4}$ yang termodifikasi dengan polimer PEG-4000, seperti yang ditunjukkan pada gambar 1. Pengujian struktur kristal dilakukan dengan menggunakan difraktometer sinar-X (XRD) dan 
panjang gelombang sinar-X yang digunakan yaitu 1.5406 Á. Sifat kristalin dari sampel nanopartikel $\mathrm{Fe}_{3} \mathrm{O}_{4}$ ditunjukkan dengan munculnya puncak-puncak difraksi seperti pada gambar 1 (a) yaitu (220) (311) (400) (511) (440) dengan puncak utama pada indeks (311). Perbandingan puncak-puncak difraksi dapat kita lihat melalui tabel 1. yang menunjukkan indeks miller dan jarak antarbidang struktur kristal untuk bahan $\mathrm{Fe}_{3} \mathrm{O}_{4}$.

Tabel 1. Indeks Miller dan jarak antarbidang pada struktur Kristal bahan $\mathrm{Fe}_{3} \mathrm{O}_{4}$

\begin{tabular}{|c|c|c|}
\hline No & $\begin{array}{l}\text { Indeks Miller } \\
(h k l)\end{array}$ & $\begin{array}{c}\text { Jarak antarbidang } \\
d(\mathrm{pm})\end{array}$ \\
\hline 1 & $\left(\begin{array}{lll}1 & 1 & 1\end{array}\right)$ & 485,2 \\
\hline 2 & $\left(\begin{array}{lll}2 & 2 & 0\end{array}\right)$ & 296,7 \\
\hline 3 & $\left(\begin{array}{lll}3 & 1 & 1\end{array}\right)$ & 253,2 \\
\hline 4 & $\left(\begin{array}{lll}2 & 2 & 2\end{array}\right)$ & 242,4 \\
\hline 5 & $\left(\begin{array}{lll}4 & 0 & 0\end{array}\right)$ & 209,9 \\
\hline 6 & $\left(\begin{array}{lll}4 & 2 & 2\end{array}\right)$ & 171,5 \\
\hline 7 & $\left(\begin{array}{lll}5 & 1 & 1\end{array}\right)$ & 161,6 \\
\hline 8 & $(440)$ & 148,5 \\
\hline
\end{tabular}

\begin{tabular}{|c|c|c|}
\hline 9 & $\left(\begin{array}{lll}5 & 3 & 1\end{array}\right)$ & 141,9 \\
\hline 10 & $\left(\begin{array}{lll}6 & 2 & 0\end{array}\right)$ & 132,8 \\
\hline
\end{tabular}

Puncak difraksi dengan indeks Miller tersebut merupakan indeks khas dari struktur kubik spinel $\mathrm{Fe}_{3} \mathrm{O}_{4}$ yang selalu muncul dalam difraktogram XRD bahan nanopartikel $\mathrm{Fe}_{3} \mathrm{O}_{4}$ [4]. Semakin tajam puncak difraksi menunjukkan sifat kristalin yang semakin baik. [5].

Ketika sampel nanopartikel $\mathrm{Fe}_{3} \mathrm{O}_{4}$ dimodifikasi dengan polimer PEG-4000, muncul puncak-puncak difraksi yang baru seperti puncak dengan indeks (111), puncak $\alpha-\mathrm{Fe}_{3} \mathrm{O}_{4}$, puncak $\gamma-\mathrm{FeO}(\mathrm{OH})$ dan puncak $\alpha-\mathrm{FeO}(\mathrm{OH})$. Munculnya puncak-puncak baru tersebut disebabkan oleh pengaruh polimer PEG-4000 yang secara langsung menunjukkan ikatan dengan gugus $-\mathrm{OH}$ (hidroksil).

Berdasarkan persamaan Scherrer. diperoleh ukuran butir nanopartikel seperti pada tabel 2.

Tabel 2. Ukuran butir nanopartikel $\mathrm{Fe}_{3} \mathrm{O}_{4}$ dan nanopartikel $\mathrm{Fe}_{3} \mathrm{O}_{4}$ yang di modifikasi dengan PEG4000

\begin{tabular}{|c|c|c|c|c|c|c|c|c|c|}
\hline Sampel & $\begin{array}{l}\text { B } \\
(0)\end{array}$ & $\begin{array}{c}\text { B } \\
\text { (rad) }\end{array}$ & $2 \theta$ & $\theta$ & $\operatorname{Cos} \theta$ & $\begin{array}{c}\text { B } \\
\cos \theta\end{array}$ & $\begin{array}{c}\lambda \\
(\mathrm{nm})\end{array}$ & $\begin{array}{c}\mathbf{k} \\
\text { (faktor) }\end{array}$ & $\begin{array}{c}\mathrm{t} \\
(\mathrm{nm})\end{array}$ \\
\hline $\mathrm{Fe}_{3} \mathrm{O}_{4}$ & 0,5787 & 0,0101 & 35,7826 & 17,8913 & 0,9516 & 0,0096 & 0,15406 & 0,9 & 14,4 \\
\hline $\mathrm{Fe}_{3} \mathrm{O}_{4}+\mathrm{PEG}$ & 0,7530 & 0,0131 & 35,9017 & 17,9508 & 0,9513 & 0,0125 & 0,15406 & 0,9 & 11,1 \\
\hline
\end{tabular}

\section{Kesimpulan}

Berdasarkan penelitian yang telah dilakukan dapat disimpulkan bahwa sintesis material yang berbahan dasar senyawa hidrat FeSO $4.7 \mathrm{H}_{2} \mathrm{O}, \quad \mathrm{FeCl}_{3} .6 \mathrm{H}_{2} \mathrm{O}$, dan $\mathrm{NH}_{4} \mathrm{OH}$ menggunakan metode kopresipitasi dapat menghasilkan material nanopartikel $\mathrm{Fe}_{3} \mathrm{O}_{4}$. Hasil karakterisasi nanopartikel $\mathrm{Fe} 3 \mathrm{O} 4$ menggunakan X-Ray Difractometer menunjukkan puncak-puncak difraksi yaitu (220) (311) (400) (511) (440) dengan puncak utama pada indeks (311). Semakin tajam puncak difraksi menunjukkan sifat kristalin yang semakin baik. Sampel nanopartikel $\mathrm{Fe}_{3} \mathrm{O}_{4}$ dimodifikasi dengan polimer PEG-4000, muncul puncak-puncak difraksi yang baru seperti puncak dengan indeks (111), puncak $\alpha-\mathrm{Fe}_{3} \mathrm{O}_{4}$, puncak $\gamma$-FeO(OH) dan puncak $\alpha-\mathrm{FeO}(\mathrm{OH})$.
Munculnya puncak-puncak baru tersebut disebabkan oleh pengaruh polimer PEG-4000 yang secara langsung menunjukkan ikatan dengan gugus - $\mathrm{OH}$ (hidroksil).

\section{Daftar Pustaka}

1. Guimaraes, A. P., Principles of Nanomagnetism, Heidelberg, Springer, 2009.

2. Riyanto, A., Sintesis Nanopartikel $\mathrm{Fe}_{3} \mathrm{O}_{4}$ dan Potensinya sebagai Material Aktif pada Permukaan Sensing Biosensor Berbasis SPR, Tesis, Program Pascasarjana, Universitas Gadjah Mada, Yogyakarta, 2012.

3. Day, R, A, Jr.; Underwood, A, L., Analisis Kimia Kuantitatif (diterjemahkan oleh Iis Sopyan), Edisi 6, Jakarta, Erlangga, , 2001. 
4. Lopez, J.A.; Gonzalez, F.; Bonilla, F. A.; Zambrano, G.; Gomez, M. E., Synthesis and Characterization of $\mathrm{Fe}_{3} \mathrm{O}_{4}$ Magnetic Nanofluid, Revista Latinoamericana de Metalurgia y Materiales, 201030 (1): 60-66.

5. Cullity B.D., Elements of X-Ray Diffraction, United States of America, John Wiley \& Sons, Inc, 1956. 